\title{
O DIREITO À EDUCAÇÃO NA NORMATIVA INTERNACIONAL DE PROTEÇÃO DOS DIREITOS HUMANOS E SUA REGULAÇÃO NO ORDENAMENTO JURÍDICO NACIONAL: ANÁLISE PRELIMINAR A PARTIR DA DECLARAÇÃO UNIVERSAL DOS DIREITOS HUMANOS E DO PACTO INTERNACIONAL DOS DIREITOS ECONÔMICOS, SOCIAIS E CULTURAIS
}

Maria Creusa de Araújo Borges

Professora e Pesquisadora do Programa de Pós-Graduação em Ciências Jurídicas da Universidade Federal da Paraíba/Brasil. Editora Adjunta da Revista Prima Facie Direito História e Política. Líder do Grupo de Estudos e Pesquisas em Educação e Direitos Humanos, certificado pelo CNPq.

\section{Resumo}

Examina-se, neste artigo, a questão do direito à educação, a partir da Declaração Universal dos Direitos Humanos (1948) e do Pacto Internacional dos Direitos Econômicos, Sociais e Culturais (1966). No direito interno brasileiro, são analisadas a Constituição Federal de 1988 e a Lei de Diretrizes e Bases da Educação Nacional de 1996, no que tange à regulação da matéria educação, em interação com os instrumentos internacionais em referência. Destaca-se que a regulação da matéria, no âmbito nacional, é influenciada pelo reconhecimento desse direito na normativa internacional, mas avança no reconhecimento do direito à educação superior de grupos sociais marginalizados, ampliando a obrigatoriedade e a gratuidade para além do ensino elementar, pois, no caso brasileiro, a educação básica é obrigatória e o princípio da gratuidade rege todo o sistema de ensino nos estabelecimentos oficiais. Configura-se, dessa forma, a existência de um núcleo essencial no tocante ao direito à educação, que é plenamente exigível.

\section{Palavras-chave}

Direito à Educação; Declaração Universal dos Direitos Humanos; Pacto Internacional dos Direitos Econômicos, Sociais e Culturais; Constituição Federal de 1988.

\section{Abstract}

We examine, in this article, the question of the right to education, from the Universal Declaration of Human Rights (1948) and the International Covenant on Economic, 
Social and Cultural Rights (1966). In the Brazilian national law, they are analyzed the Federal Constitution of 1988 and the Law of Guidelines and Bases of National Education, 1996, regarding the regulation of education matter, in coordination with the international instruments in question. It is noteworthy that the regulation of the matter at the national level, is influenced by the recognition of this right in international norms, but advances in the recognition of the right to higher education of marginalized social groups, expanding the mandatory gratuity and beyond elementary school because in the Brazilian case, basic education is compulsory and the principle of free governs the entire education system in official establishments. Set up in this way, the existence of an essential core regarding the right to education, which is fully chargeable.

\section{Key words}

Right to Education; Universal Declaration of Human Rights; International Covenant on Economic, Social and Cultural Rights; The Constitution of 1988.

\section{Introdução}

A concepção de educação como um direito humano alcança centralidade no contexto após Segunda Guerra. Com a criação da Organização das Nações Unidas (ONU), em 1945, é produzida uma normativa internacional de proteção dos direitos humanos com destaque, entre outros direitos, à afirmação do direito à educação. Esta assume tarefa fundamental na construção de uma nova ordem, pautada numa agenda construída pelos vencedores da guerra, os Aliados. Assim, a educação, por um lado, é reiteradamente reconhecida como um direito humano. Por outro, é pensada como um instrumento de formação em direitos humanos, formação esta fundamentada nos valores assumidos pela ONU no seu projeto de cooperação entre os Estados e de construção da paz. Nesse cenário, são aprovados instrumentos internacionais de direitos humanos que reconhecem o direito à educação, em vários níveis, do ensino elementar aos níveis mais elevados, como é a educação superior.

Nesse contexto, são analisados dois instrumentos normativos internacionais: a Declaração Universal dos Direitos Humanos (1948) e o Pacto Internacional dos Direitos Econômicos, Sociais e Culturais (1966). Não obstante o fato de que esses instrumentos foram aprovados em contextos diferentes, marcados por tensóes específicas, e da natureza jurídica diversa, a Declaração e o Pacto supracitados constituem uma normativa relevante no processo de afirmação de direitos humanos. Além disso, a partir da Declaração, até os nossos dias, a educação é normatizada como um direito humano e um bem público, concepção encabeçada pela Organização das Naçóes Unidas para a Educaçáo, a Ciência e a Cultura (UNESCO), agência especializada da ONU. 
Por sua vez, é analisada a normativa nacional quanto à matéria, numa perspectiva comparada com a normativa da ONU, representada pela Declaração e pelo Pacto supras. Nessa análise, são identificados avanços e recuos no processo de afirmação da educação como um direito humano. Identifica-se, também, que, em determinados aspectos, a normativa nacional avança muito mais que a internacional, consolidando conteúdos do núcleo essencial do direito à educação.

\section{Declaração Universal dos Direitos Humanos e 0 Direito à Educação}

O movimento contemporâneo relativo aos direitos humanos toma impulso decisivo com a aprovação da Declaração Universal dos Direitos Humanos (DUDH), em 10 de dezembro de 1948, em Paris, pela Assembleia Geral das Naçôes Unidas ${ }^{1}$. A partir desse documento, os países ocidentais, os Aliados, vencedores da Segunda Grande Guerra, intitulados de Naçóes Unidas, estabelecem uma agenda, no cenário internacional, de reconhecimento e de proteção dos direitos humanos. Por intermédio do trabalho legislativo da Organização das Naçóes Unidas (ONU) e da atuação de seus diversos órgáos e das agências especializadas, os direitos humanos passam a ser uma área de preocupação internacional, cuja proteção é assumida como propósito das Naçóes Unidas, proteção afirmada em sua Carta, instrumento constitutivo da referida organizaçáo supranacional.

Na condição de documento-símbolo, “(...) ponto de partida do processo de generalização da proteção internacional dos direitos humanos (...)" (CANÇADO TRINDADE, 1997 , p. 28), padrão comum de reconhecimento e de proteção dos direitos humanos (ALVES, 2007), a Declaração representa o registro histórico, político e jurídico da repulsa às violaçóes aos direitos humanos cometidas por Estados totalitários no âmbito da Segunda Grande Guerra. Indica, portanto, a construção de uma nova ordem mundial ${ }^{2}$, baseada em relaçóes democráticas e pacíficas entre os Estados, ordem que tem por fundamento a proteção dos direitos da pessoa humana.

Essa nova ordem baseia-se, juridicamente, na Carta da ONU, documento que estabelece os propósitos e as diretrizes de atuação das Nações Unidas no cenário internacional. Assim, a Carta consiste numa referência no processo de formulaçáo dos instrumentos internacionais de proteção dos direitos humanos, os quais resultam tanto do trabalho legislativo das Nações Unidas, como de outras organizaçóes de caráter regional, como é o caso da

1 A DUDH foi adotada e proclamada pela resolução 217 A (III) da Assembléia Geral da ONU.

2 As "Quatro Liberdades"- liberdade de palavra, liberdade de crença e liberdade de viverem a salvo do temor e da necessidade -, afirmadas pelo Presidente Roosevelt, no discurso "Estado da União", proferido no Congresso dos Estados Unidos da América, em 6 de janeiro de 1941, constituem a base da nova ordem mundial, a ser liderada pelos Aliados, vencedores da Segunda Grande Guerra. As liberdades supracitadas foram incorporadas ao preâmbulo da DUDH. Sobre a história da formulação da DUDH, consultar: Poole et al (2007). 
Organização dos Estados Americanos (OEA). Esses instrumentos, que possuem natureza e efeitos jurídicos variáveis, são influenciados pelos princípios assumidos na Carta, sendo esta explicitada em vários preâmbulos de instrumentos internacionais de direitos humanos desde a aprovação da Declaração de 1948. Portanto, a compreensão da Declaração requer a sua articulação com os princípios, objeto e propósitos afirmados na Carta de São Francisco.

$\mathrm{Na}$ Carta, não estão descritos e catalogados os direitos humanos, tarefa levada a cabo pelo comitê de redação, responsável pela elaboração da DUDH. Diante da lacuna presente nos dispositivos da Carta da ONU, em relação à definição dos direitos humanos a serem objeto de proteção, a Declaração passa a se constituir em fonte de interpretação dos dispositivos acerca dos direitos humanos afirmados na Carta. Configura-se, dessa maneira, uma interação entre as declaraçóes de direitos humanos e os instrumentos constitutivos de organizaçóes internacionais, de caráter universal, como é o caso da ONU, e de abrangência regional, como a OEA (CANÇADO TRINDADE, 1997).

A escrita da Declaração envolveu o trabalho de vários órgãos, antes de sua submissão à Assembléia Geral. Assim, o Conselho Econômico e Social das Naçóes Unidas (ECOSOC) encaminhou a sua subseção, a Comissão de Direitos Humanos (CDH), sob a liderança de Eleanor Roosevelt, o trabalho de escrita de uma declaração internacional, pois o plano geral era de elaboração de uma Carta Internacional de Direitos Humanos, na qual a DUDH seria uma parte, considerada mais como uma declaração de princípios, no estilo de preâmbulo, complementada por disposiçóes substantivas, constantes nos instrumentos obrigatórios, tais como o Pacto Internacional de Direitos Econômicos, Sociais e Culturais (PIDESC) e o Pacto Internacional de Direitos Civis e Políticos (PIDCP), ambos de 1966.

A CDH encarregou o comitê de redação - composto por representantes da Austrália, China, Chile, Filipinas, França, Iugoslávia, Líbano, Reino Unido, República Socialista Soviética, Uruguai - de elaboração de um esboço da Declaração para ser submetido ao ECOSOC. Este encaminhou a proposta à Assembléia Geral, órgão legislativo principal da ONU, onde cada membro tem direito a voto, com peso igual (ALVES, 2007).

No processo de escrita da Declaração, a Organização das Naçóes Unidas para a Educação, Ciência e Cultura (UNESCO) desempenhou papel relevante (CANÇADO TRINDADE, 1997; POOLE ET AL, 2007). Ao examinar os principais problemas teóricos relativos à formulação da Declaração, esta agência especializada da ONU explicitou questóes referentes às relaçóes entre liberdades individuais e responsabilidades coletivas, questóes que perpassam a problemática dos direitos humanos na contemporaneidade ${ }^{3}$, interferindo no seu processo de reconhecimento e efetivação.

3 Sobre a matéria, consultar o documento: Los Derechos del Hombre- estudios y comentarios en torno a la nueva declaración universal reunidos por la UNESCO. México/Buenos Aires: Fondo de Cultura Económica, 1949, apêndice I, pp. 227-232. 
A Declaração, elaborada em menos de dois anos, nas três primeiras sessóes da CDH, foi aprovada na primeira sessão da Assembleia Geral a que foi submetida (a III Assembleia Geral das Naçôes Unidas). Dos 58 Estados-Membros, 48 votaram a favor, nenhum contra, 8 se abstiveram ${ }^{4}$ e 2 se ausentaram da ocasiáo (RANGEL, 2005). Portanto, a relevância desse documento não advém do quantitativo dos Estados que a aprovaram, mas, sobretudo, do fato de que representa a formulação jurídica da noção de direitos inerentes à pessoa humana - afirmada, mas não detalhada na Carta da ONU - formulação alçada ao plano internacional a partir da aprovação da DUDH (CANÇADO TRINDADE, 1997). $\mathrm{Na}$ qualidade de "(...) primeira expressão dos direitos humanos de forma abrangente em escala internacional" (POOLE ET AL, 2007, p. 91), a DUDH, definitivamente, coloca o ser humano no cerne do debate político internacional, reconhecendo que a proteção dos direitos humanos se constitui em preocupação dos Estados, independentemente da condição desfrutada pelo ser humano (nacional ou estrangeiro; rico ou pobre).

Uma questão recorrente, na doutrina, consiste na natureza jurídica da Declaração. Comumente, na prática internacional, as declarações não apresentam força jurídica obrigatória, característica atribuída aos tratados, convençóes e pactos. Entretanto, Alves (2007) chama à atenção para a peculiaridade da DUDH. Pelo fato de conter referência explícita, em seu preâmbulo, às disposiçóes da Carta da ONU, esta última de caráter obrigatório, e pela existência do fenômeno da conversão da Declaração em norma consuetudinária, não autoriza a afirmação da DUDH como meramente uma declaração de princípios, sem quaisquer elementos coativos e obrigatórios.

(...) o que se verifica na prática é a invocação generalizada da Declaração Universal como regra dotada de jus cogens, invocação que não tem sido contestada sequer pelos Estados mais acusados de violaçóes de seus dispositivos (ALVES, 2007, p. 48).

Aprovada sob a forma de uma resolução não-impositiva da Assembleia Geral, a Declaração não possui força vinculante. Contudo, na mesma lógica de Alves (2007), Poole et al (2007) reconhecem a existência de elementos coativos, tanto internamente como externamente, na DUDH. No plano interno, se distingue, na Declaração, preâmbulo e artigos, muitos desses se constituindo em obrigaçóes, a base dos artigos obrigatórios dos Pactos de 1966. Externamente, a DUDH consiste numa grande referência no direito internacional, influenciando a produção normativa sobre a matéria, constituindo-se em referência explícita em diversos instrumentos internacionais que a sucedem. $\mathrm{O}$ impacto da DUDH ainda foi mais considerável pela demora no processo de aprovação dos Pactos de 1966 - um lapso de tempo de 18 anos - pactos que são considerados, pela doutrina,

4 Abstençôes da África do Sul, Arábia Saudita, Bielorrússia, Iugoslávia, Polônia, Tchecoslováquia, Ucrânia e União Soviética. 
como vinculantes e obrigatórios. Entretanto, o tempo prolongado para a aprovação dos referidos Pactos:

(...) contribuiu para florescer a tese de que alguns dos princípios da Declaração cedo se afiguravam como parte do direito internacional consuetudinário, ou como expressão dos princípios gerais do direito, invocados em processos nacionais e internacionais (CANÇADO TRINDADE, 1997, p. 38).

Cançado Trindade (1997) examina o valor jurídico e o alcance da Declaração Universal. Para o autor, a DUDH consiste num instrumento decisivo, ao servir como modelo e ponto de partida para o processo de generalização da proteção internacional relativa aos direitos humanos. Processo de generalizaçáo marcado pela proteçáo do ser humano náo mais restrita a determinadas condiçóes ou a setores circunscritos, como no caso da proteção dos trabalhadores sob a égide das primeiras convenções da Organização Internacional do Trabalho (OIT). Nesse processo, presencia-se a proliferação de diversos tratados sobre a matéria, em que a DUDH se constitui numa referência explícita, sendo citada literalmente nos preâmbulos de diversas convençôes 5 .

A Declaração Universal afigura-se, assim, como a fonte de inspiração e um ponto de irradiaçáo e convergência dos instrumentos sobre direitos humanos em níveis tanto global quanto regional. Este fenômeno vem a sugerir que os instrumentos globais e regionais sobre direitos humanos, inspirados e derivados de fonte comum, se complementam (...) (CANÇADO TRINDADE, 1997, p.43).

Portanto, o valor jurídico da DUDH não pode ser minimizado. A interação interpretativa entre a Declaração e a Carta da ONU e outros instrumentos constitutivos de organizações internacionais e de base convencional, além de sua incorporação nos ordenamentos jurídicos estatais, indica a posição de destaque da DUDH no sistema normativo internacional e nacional relativo aos direitos humanos.

Nesse âmbito, os direitos humanos, afirmados na Declaração, são objeto de várias propostas de classificação. Uma dessas propostas, aqui adotada, consiste na classificação realizada por Donnelly (1986). De acordo com essa proposta, os direitos em tela são classificados em direitos pessoais; direitos judiciais; liberdades civis; direitos de subsistência;

5 Convención relativa a la lucha contra las discriminaciones en la esfera de la enseńanza (1960); Convención Internacional sobre la Eliminación de todas las Formas de Discriminación Racial (1965); Pacto Internacional de Derechos Económicos, Sociales y Culturales (1966); Pacto Internacional de Derechos Civiles y Políticos (1966); Convención Internacional sobre la Represión y el Castigo del Crimen de Apartheid (1973); Convención sobre la Eliminación de todas las Formas de Discriminación contra la Mujer (1979); Convención sobre los Derechos del Niño (1989). 
direitos econômicos; direitos sociais e culturais; direitos políticos. A seguir, resume-se, sucintamente, o leque de direitos humanos classificados conforme a proposta em tela.

Integram os direitos pessoais (arts. $2^{\circ}$ a $7^{\circ}$ e 15): o direito à vida; à nacionalidade; ao reconhecimento da personalidade jurídica; à igualdade de proteção perante a lei; à proteção contra tratamentos cruéis, desumanos ou degradantes; à proteção contra a discriminação racial, étnica, sexual ou religiosa.

Os direitos judiciais (arts. $8^{\circ}$ a 12) referem-se: ao acesso a remédios por violaçóes de direitos reconhecidos em lei; à presunção da inocência; à garantia de um processo público, imparcial, dirigido por um tribunal competente e independente; à irretroatividade das leis penais; à proteção contra prisóes ou exílios arbitrários; à proteção contra ingerências na privacidade, na família, no domicílio, na correspondência, na reputação.

As liberdades civis (art. 13 e arts. 18 a 20) consistem nas liberdades de: circular livremente no território de um Estado; pensamento; consciência; religião; reunião e associação pacíficas.

Os direitos de subsistência (art. 25) referem-se aos direitos à alimentação e a um padrão de vida adequado; à saúde e ao bem-estar próprio e da família.

Integram os direitos econômicos (arts. 22 a 26): o direito ao trabalho, com remuneração equitativa e condiçôes adequadas; à associação sindical; ao descanso e ao lazer. Nesta classificação, o autor exclui o direito à propriedade, regulado no artigo 17 da Declaração Universal.

Os direitos sociais e culturais (arts. 26 a 28) são constituídos pelos direitos à educação; à participação livre na vida cultural da comunidade e nos resultados do progresso científico.

Os direitos políticos (art. 21) referem-se: à participação livre no governo, por intermédio de representantes eleitos; ao acesso, em condiçóes de igualdade, às funçóes públicas.

Os direitos humanos, reconhecidos na Declaração, ainda podem ser relacionados em dois grupos: os direitos civis e políticos (arts. $3^{\circ}$ a 21) e os direitos econômicos, sociais e culturais (arts. 22 a 28) (ALVES, 2007). Esta categorização é largamente utilizada na doutrina e na jurisprudência internacionais de direitos humanos.

Distinguem-se, na DUDH, o preâmbulo, no qual se encontram as motivaçóes políticas, consistindo na base da Declaração, e trinta artigos. Nestes, são objeto de regulação os direitos civis, políticos, econômicos, sociais e culturais. Adota-se a concepção de que todos os seres humanos nascem livres e iguais em dignidade e direitos (DUDH, art. 1), afirmando-se a perspectiva de que os direitos humanos consistem em direito de todos, sem distinção alguma (art. 2). 
Em relação à matéria educação, esta é discutida, inicialmente, no preâmbulo. Nesta parte, destaca-se que "el desconocimiento y el menosprecio de los derechos humanos han originado actos de barbarie ultrajantes para la conciencia de la humanidad" (DUDH, PREÂMBULO). Assim, explicita-se, mais uma vez ${ }^{6}$, a referência às atrocidades cometidas aos seres humanos no contexto da Segunda Grande Guerra. Relaciona-se a ocorrência de violaçôes aos direitos humanos à ausência de conhecimento sobre esses direitos. A Declaração, portanto, confere à educação um papel relevante na construção de uma nova ordem internacional, pautada no respeito aos direitos humanos. Assim, exige-se um trabalho educativo voltado para a conscientização sobre os direitos da pessoa humana, evitando-se a ocorrência de outros atos de barbárie, tais como aqueles ocorridos no supracitado conflito mundial.

Reconhece-se, no preâmbulo da Declaração, que "una concepción común de estos derechos y libertades (...)" assume relevância fundamental para que os Estados, em cooperação com as Naçóes Unidas, cumpram com o compromisso de assegurar o respeito universal e efetivo aos direitos humanos. Assim, o conhecimento e a conscientização sobre os direitos humanos são colocados, reiteradamente, como uma forma de prevenção de novas violaçóes a esses direitos.

Com base nessa compreensão, a Assembleia Geral da ONU proclama a DUDH, como um ideal comum, uma fonte de inspiração para que as naçóes promovam, por intermédio do ensino e da educação, o respeito aos direitos humanos. A noção de ensino remete às atividades realizadas na escola, no âmbito formal. Por sua vez, a educação compreendida como uma prática social, que se realiza além do espaço escolar, abrangendo as práticas culturais, dos movimentos sociais, o trabalho, entre outras ${ }^{7}$.

O direito à educação encontra-se regulado, na Declaração, no artigo 26:

1. toda persona tiene derecho a la educación. La educación debe ser gratuita, al menos en lo concerniente a la instrucción elemental y fundamental. La instrucción elemental será obligatoria. La instrucción técnica y profesional habrá de ser generalizada; el acceso a los estudios superiores será igual para todos, en función de los méritos respectivos. 2. La educación tendrá por objeto el pleno desarrollo de la personalidad humana y el fortalecimiento del respeto a los derechos humanos y a las libertades fundamentales; favorecerá la comprensión, la tolerância y la amistad entre todas las naciones y todos los grupos étnicos o religiosos; y promoverá

6 A primeira referência explícita encontra-se na Carta das Naçôes Unidas.

7 Na Lei de Diretrizes e Bases da Educação Nacional(LDB), Lei no 9.394/96, em seu artigo 1º, afirma-se uma concepção ampla de educação, sendo esta compreendida como uma prática social que extrapola os 'muros' da escola, não obstante a referida Lei regular as práticas que se desenvolvem, predominantemente, em espaços escolares. 
el desarrollo de las actividades de las Naciones Unidas para el mantenimiento de la paz. 3. Los padres tendrán derecho preferente a escoger el tipo de educación que habrá de darse a sus hijos.

A educação é afirmada como um direito de todos. Segue-se, assim, a perspectiva assumida pelas Nações Unidas de que os direitos humanos são para todos, sem distinção de raça, etnia, sexo, idioma, religião, opinião política, nacionalidade, posição econômica, nascimento ou qualquer outra condição (CARTA DA ONU, art. 1; DUDH, art. 2).

No ordenamento jurídico nacional, a concepção de que a educação é um direito de todos é reiterada na Constituição Federal de 1988 (CF, 1988):

a educação, direito de todos e dever do Estado e da família ${ }^{8}$, será promovida e incentivada com a colaboração da sociedade, visando ao pleno desenvolvimento da pessoa, seu preparo para o exercício da cidadania e sua qualificação para o trabalho (CF/88, art. 205).

Não obstante a afirmação da concepção de educação como um direito de todos, reconhece-se, de forma restrita, o princípio da gratuidade. Este princípio deve nortear toda a educação, mas estabelece-se que essa gratuidade deve ser concretizada pelo menos na instrução elementar e fundamental.

No ordenamento jurídico nacional, há uma especificidade. A gratuidade é reconhecida como um princípio, de hierarquia constitucional, que deve nortear toda a educação pública. Consiste, como afirma o Ministro do Supremo Tribunal Federal (STF), Ricardo Lewandowski, em parecer de 2008, em núcleo axiológico do sistema de ensino brasileiro. Portanto, não se restringe a uma etapa da educação, devendo está presente na educação básica e superior. É o que se afirma na CF, art. 206, IV: “o ensino será ministrado com base nos seguintes princípios: (...) IV-gratuidade do ensino público nos estabelecimentos oficiais (...)".

A afirmação da obrigatoriedade é enfática na Declaração de 1948, referindo-se à instrução elementar. No caso brasileiro, a obrigatoriedade incide na educação básica, esta compreendida como obrigatória e gratuita dos quatro aos dezessete anos, assegurada sua oferta gratuita para todos aqueles que não tiveram acesso na idade própria ${ }^{9}$ (CF, art. 208, I). $\mathrm{O}$ acesso ao ensino obrigatório e gratuito constitui direito público subjetivo e o seu não-oferecimento ou sua oferta irregular por parte do Estado implica em responsabilidade da autoridade competente (CF, art. 208, $\$ \$ 1^{\circ}$ e $2^{\circ}$ ).

8 Na Lei de Diretrizes e Bases da Educação Nacional (Lei no 9.394/96), essa relação se inverte, passando a educação a se constituir, primeiramente, em dever da família (art. 2o).

9 Redação dada pela Emenda Constitucional no 59 , de 2009. 
O ensino profissionalizante, conforme a DUDH, deverá ser generalizado. No caso brasileiro, essa modalidade de ensino não é contemplada no art. 208 da CF, artigo que regula o dever do Estado em relação à educação. Na LDB/96, no Capítulo III, é feita referência à educação profissional, que deve ser oferecida de forma integrada às diferentes formas de educação e visa ao desenvolvimento de aptidóes para a vida produtiva (art. 39).

$\mathrm{Na}$ DUDH, o acesso aos estudos superiores é possibilitado, de forma igual, a todos, orientando-se pelo mérito individual. $\mathrm{Na} \mathrm{CF} / 88$, o acesso aos níveis mais elevados de ensino pauta-se na capacidade individual. Reitera-se, a concepção de educação superior como um direito de todos, cujo acesso depende da capacidade do indivíduo. Retira-se, assim, a responsabilidade do Estado de garantir o acesso aos estudos superiores, colocando essa responsabilidade para o indivíduo.

Na Declaração, também, são colocados os objetivos da educação. Esta deverá promover o desenvolvimento da personalidade humana. Tendo como referência os propósitos das Naçóes Unidas, a educação deve fortalecer o respeito aos direitos humanos e colaborar nas atividades da ONU em prol da manutenção da paz. Aos pais cabe a escolha do tipo de educação para os seus filhos, colocando-se para a família a responsabilidade de participar do processo educativo. Nesse caso, a LDB (1996) é enfática ao afirmar que a educação constitui, primeiramente, dever da família (art. 2º).

Percebe-se que o reconhecimento do direito à educação, na DUDH, se dá de forma ampla, abarcando várias etapas e níveis de educação. Entretanto, esse reconhecimento não ocorre de maneira igual, restringindo-se à garantia desse direito para os níveis elementares, deixando a responsabilidade de acesso aos níveis superiores para o indivíduo, com base no critério do mérito individual. No ordenamento jurídico brasileiro, o acesso aos estudos superiores pauta-se na capacidade individual, não obstante a adoção de sistema de cotas no acesso à universidade pública, cuja constitucionalidade foi decidida pelo STF, na Arguição de Descumprimento de Preceito Fundamental, ADPF no 186, cujo julgamento ocorreuem 2012 ${ }^{10}$. Posteriormente, foi aprovada a Lei no 12.711, em 2012, a chamada Lei de Cotas, garantindo a reserva de vagas para alunos oriundos do ensino médio público no acesso à educação superior pública brasileira.

10 ADPF proposta pelo partido político Democratas (DEM) contra atos administrativos da Universidade de Brasília, a qual instituiu um programa de cotas raciais para o acesso à universidade. Na ação, o DEM alega ofensa à CF (1988), precisamente, aos artigos $1^{\circ}$, caput e inciso III; $3^{\circ}$, inciso IV; 37, caput; 205; 207, caput; e 208, inciso V. O Ministro Relator do caso, em seu voto apreciando a matéria, decide: “(...) considerando, em especial, que as políticas de ação afirmativa adotadas pela Universidade de Brasília (i) têm como objetivo estabelecer um ambiente acadêmico plural e diversificado, superando distorçôes sociais historicamente consolidadas, (ii) revelam proporcionalidade e a razoabilidade no concernente aos meios empregados e aos fins perseguidos, (iii) são transitórias e prevêem a revisão periódica de seus resultados, e (iv) empregam métodos seletivos eficazes e compatíveis com o princípio da dignidade humana, julgo improcedente esta ADPF” (LEWANDOWSKI, 2012). 
Percebe-se que a educação, na DUDH, assume papel fundamental no desenvolvimento dos propósitos das Naçóes Unidas: promoção do respeito aos direitos humanos, por meio de um trabalho educativo de conhecimento e de conscientização; atividades em prol da manutenção da paz e da segurança internacionais, por intermédio, inclusive, da cooperação de caráter científico e educacional, liderada pela UNESCO.

A afirmação do direito à educação na DUDH, mesmo não se constituindo em obrigaçóes de caráter convencional para os Estados, influencia, como visto, a regulação desse direito nos ordenamentos jurídicos nacionais. Questôes referentes à gratuidade, obrigatoriedade, colocadas na Declaração, repercutem na configuração do dever do Estado em matéria educacional. No caso brasileiro, não obstante a obrigatoriedade se restringir à educação básica, o princípio da gratuidade constitui uma referência fundamental do sistema de ensino brasileiro, abarcando todas as etapas do percurso educacional em estabelecimentos oficiais.

\section{0 Pacto Internacional dos Direitos Econômicos, Sociais e Culturais e o Direito à Educação}

A atualização da DUDH realiza-se por intermédio da elaboração de novos instrumentos internacionais de proteção dos direitos humanos, tais como o Pacto Internacional de Direitos Econômicos, Sociais e Culturais (PIDESC) e o Pacto Internacional de Direitos Civis e Políticos (PIDCP), aprovados pela Assembleia Geral da ONU em 16 de dezembro de 1966. A decisão da Assembleia das Naçôes Unidas, em 1951, de elaborar dois Pactos, ao invés de um, indica a tensão, presente à época, entre duas teses existentes acerca da aplicabilidade entre os diferentes conjuntos de direitos humanos, como, também, a ocorrência de conflitos de caráter ideológico - que influenciaram os trabalhos preparatórios dos referidos Pactos - conflitos liderados pelos dois blocos político-econômicos da Guerra Fria: o bloco capitalista, encabeçado pelos Estados Unidos, e o bloco comunista, sob a liderança da então União Soviética (CANÇADO TRINDADE, 1997).

No contexto de formulação dos Pactos de 1966, vigorava a perspectiva de que os direitos civis e políticos eram dotados de aplicabilidade imediata, restando aos Estados, no tocante à efetivação desses direitos, obrigaçóes de cunho negativo. Ou seja, esses direitos, para serem aplicados, exigiam, apenas, a abstenção por parte do Estado, deixando uma margem de liberdade de atuação individual para a concretização dos direitos civis e políticos. Por sua vez, os direitos econômicos, sociais e culturais eram compreendidos como direitos passíveis de aplicação, apenas, progressiva, requerendo, para a sua efetivação, a prestação estatal positiva (CANÇADO TRINDADE, 1997).

Entretanto, essa dicotomia quanto à aplicabilidade dos direitos humanos, ainda na época dos trabalhos preparatórios, não se apresentava de forma absoluta. Conforme 
Cançado Trindade (1997), o PIDCP prevê a possibilidade de aplicação progressiva de tais direitos, como o PIDESC contém dispositivos suscetíveis de aplicação imediata.

A distinção entre as diferentes categorias de direitos humanos, consolidada na elaboração dos Pactos, é reflexo, portanto, da bipolaridade, sobretudo de base ideológica, entre Estados Unidos da América e a então União Soviética, no início dos anos cinqüenta do século XX, momento em que se iniciam os trabalhos preparatórios dos referidos Pactos. Nas palavras de Cançado Trindade “(...) o então 'grupo ocidental' enfatizava os direitos civis e políticos, ao passo que o então 'bloco socialista' privilegiava os direitos econômicos, sociais e culturais" (1997, p. 355).

A categorização supracitada não foi antecipada nos trabalhos preparatórios da DUDH de 1948, pois os diferentes - mas indivisíveis - direitos humanos constavam na mesma Declaração, não obstante a ênfase nos direitos do indivíduo, reflexo das Revoluçôes liberais-burguesas do século XVIII. Na Declaração Americana de Direitos e Deveres do Homem ${ }^{11}$, também de 1948, produto do trabalho legislativo da OEA, os direitos humanos são afirmados, juntos, no mesmo instrumento.

Os Pactos de 1966 foram preparados à luz da Carta das Naçóes Unidas e da Declaração Universal dos Direitos Humanos e contêm força jurídica convencional, vinculando os Estados-partes nos referidos tratados (REZEK, 2008). Essa característica amplia as obrigaçóes dos Estados em relação aos direitos reconhecidos nos Pactos, tal como o direito à educação, regulado no PIDESC.

No PIDESC, mais especificamente no preâmbulo, é feita referência explícita à Carta da ONU, cujos princípios constituem a base de elaboração do Pacto. A Carta, também, é citada para realçar as obrigaçôes dos Estados no tocante à promoção do respeito aos direitos humanos, assumidas, primeiramente, no instrumento constitutivo da ONU.

Tendo por base a DUDH (1948), o PIDESC enfatiza a necessidade de criação de condiçóes para que o ser humano usufrua dos direitos econômicos, sociais e culturais, tanto como dos direitos civis e políticos. O gozo dos diferentes direitos humanos constitui condição para que o ser humano seja liberado do temor e da miséria.

Os direitos protegidos no PIDESC recaem, em sua maioria, na competência das agências especializadas das Naçóes Unidas, tais como a OIT e a UNESCO. O Comitê de Direitos Econômicos, Sociais e Culturais, criado por resolução do ECOSOC, face à omissão do PIDESC, assume a responsabilidade de supervisionar as obrigaçóes dos Estados-partes em relaçáo aos direitos reconhecidos no referido Pacto. Na prática, o Comitê, após examinar os relatórios dos Estados, adota as denominadas 'concluding observations',

11 Declaração que se antecipou em alguns meses à DUDH, sendo influenciada por seus trabalhos preparatórios. 
estruturadas em cinco seçôes: introdução, aspectos positivos, fatores e dificuldades que impossibilitam a implantação do Pacto, preocupaçóes principais e recomendaçóes (CANÇADO TRINDADE, 1997). O Comitê, portanto, após o exame dos relatórios enviados pelos Estados, indica recomendaçôes para que os entes estatais efetivem as obrigaçóes assumidas no Pacto em análise.

A tese das obrigações mínimas dos Estados em relação à efetivação dos direitos econômicos, sociais e culturais ainda é a perspectiva dominante na elaboração dos documentos internacionais relativos a esses direitos. Por exemplo, o trabalho do Comitê responsável pela supervisão do referido Pacto, quando do não cumprimento das obrigaçôes assumidas pelo Estado-parte, focaliza-se na formulação de observaçóes gerais sobre a situação de determinado direito. Observações e recomendaçóes que não possuem a mesma força jurídica de sançôes.

A formulação do texto legal do instrumento jurídico em análise baliza essa ideia das obrigações mínimas, como se observa a seguir:

1. cada uno de los Estados Partes en el presente Pacto se compromete a adoptar medidas, tanto por separado como mediante la asistencia y la cooperación internacionales, especialmente económicas y técnicas, hasta el máximo de los recursos de que disponga, para lograr progresivamente, por todos los medios apropiados, inclusive en particular la adopción de medidas legislativas, la plena efetividade de los derechos aquí reconocidos (...) (PIDESC, art. 2).

As obrigações contraídas pelos Estados devem ser concretizadas até o máximo dos recursos estatais disponíveis e de forma progressiva, deixando margem para os Estados decidirem as suas prioridades em relação à efetivação dos direitos econômicos, sociais e culturais. No tocante ao direito à educação, essa tese marca a sua presença, como se observa na leitura do artigo 13 do PIDESC.

1. Los Estados Partes en el presente Pacto reconocen el derecho de toda persona a la educación. (...). 2. Los Estados Partes en el presente Pacto reconocen que, con objeto de lograr el pleno ejercicio de este derecho: a) La enseñanza primaria debe ser obligatoria y asequible a todos gratuitamente; b) La enseńanza secundaria, en sus diferentes formas, incluso la enseñanza técnica y profesional, debe ser generalizada y hacerce accesible a todos, por cuantos medios sean apropiados, y en particular por la implantación progresiva de laenseñanza gratuita; c) La enseñanza superior debe hacerce igualmente accesible a todos, sobre la base de la capacidad de cada uno, por cuantos medios sean apropiados, y en particular por la implantación progresiva de la enseñanza gratuita; d) Debe fomentarse o intensificarse, en la medida de lo posible, la educación fundamental para aquellas personas que no hayan recibido o terminado el ciclo completo de 
instrucción primaria; e) Se debe proseguir activamente el desarrollo del sistema escolar en todos los ciclos de la enseńanza, implantar un sistema adecuado de becas y mejorar continuamente las condiciones materiales del cuerpo docente (...).

Não obstante o direito à educação ser reconhecido de forma extensa, inclusive abarcando aspectos não contemplados na DUDH, o exame de cada item indica que a tese das obrigações mínimas e da aplicação progressiva ainda marcam a sua presença. Primeiramente, afirma-se, como na Declaração de 1948, a educação como um direito de todos. Posteriormente, enfatiza-se o direito à educação no tocante a cada etapa do percurso educacional.

A educação obrigatória e gratuita consiste no ensino elementar, tal como afirmado na DUDH. No tocante ao ensino secundário, incluindo nesse nível a instrução técnica e profissional, reconhece-se a necessidade de sua generalização e acessibilidade a todos. Entretanto, o PIDESC amplia esse direito, ao afirmar a implantaçáo da gratuidade, de forma progressiva, neste nível de ensino. Difere, portanto, nesse aspecto, da DUDH. Reconhece-se o direito das pessoas que não concluíram o ensino primário de prosseguir seus estudos na educação fundamental, mas utiliza-se, novamente, a assertiva "na medida do possível". Enfatiza-se a necessidade de implantação de um sistema de bolsas e a melhoria contínua das condiçóes de trabalho do docente, aspectos não afirmados na DUDH.

O ensino superior deve ser, igualmente, acessível a todos, com base na capacidade individual, reiterando-se, como na DUDH, a perspectiva do mérito como critério de acesso a esse nível de escolarização. Compreende-se a educação superior como um direito de todos, mas o seu acesso pauta-se no critério da capacidade da cada um.

São reconhecidos aspectos do direito à educação não enfatizados na Declaração de 1948, tais como: implantação progressiva da gratuidade no ensino secundário e no ensino superior; garantia do direito das pessoas jovens e adultas a concluírem o ensino fundamental; bolsas de estudo; melhoria das condiçóes de trabalho do corpo docente. Por sua vez, reitera-se a capacidade individual como critério de acesso à educação superior.

Nesse âmbito, consideram-se como elementos exigíveis do direito à educação, sendo, portanto, de aplicação imediata: o direito à educação primária obrigatória e gratuita; a liberdade de escolha em matéria educacional; o direito de acesso à educação, sem qualquer discriminação. O ensino secundário e o ensino superior, cuja obrigatoriedade e gratuidade constituem princípios de aplicaçáo progressiva, ainda não podem ser totalmente exigíveis.

No caso brasileiro, constituem aspectos do direito à educaçáo de aplicaçáo imediata: educação básica obrigatória e gratuita; gratuidade do ensino público em estabelecimentos oficiais, em todas as etapas de educação, da educação básica a superior; a liberdade de escolha dos pais da educação de seus filhos; a liberdade religiosa no processo educacional; a liberdade de escolha dos métodos pedagógicos. 
Configura-se, dessa forma, a existência de um núcleo fundamental no tocante ao direito à educação, que é plenamente exigível. Assim, a tese da aplicação, apenas, progressiva dos direitos econômicos, sociais e culturais não se concretiza de forma absoluta, devendo ser considerada após a realização de exame cauteloso da matéria em pauta, em suas diferentes nuances.

\section{Conclusões}

A análise da normativa internacional focalizou a afirmação da educação como um direito humano a partir da Declaração Universal de 1948 e do Pacto Internacional dos Direitos Econômicos, Sociais e Culturais de 1966. Reconhecida, no Preâmbulo da Declaração, a educação assume papel central na construção da nova ordem internacional do Pós-Guerra, liderada pelos Aliados, vencedores do conflito mundial. Ao enfatizar que o desconhecimento sobre esses direitos contribuiu para as violaçóes de direitos humanos, sobretudo nos campos de concentração nazista, a Declaração realça, pelo menos, uma tarefa fundamental para a educação: a de promotora de valores compatíveis com uma sociedade pautada nos direitos humanos e na paz entre os Estados. Por outro ângulo, mas complementar à tarefa fundamental supra, é reconhecido o direito à educação a todos, do ensino elementar aos estudos superiores. Estes últimos pautados no acesso com mérito. Questôes chave reiteradas no Pacto de 1966.

Confrontando essa normativa internacional com a regulação interna, percebe-se uma incorporação dessas questôes na CF de 1988 e na LDB de 1996. Entretanto, em alguns aspectos, a normativa nacional avança em termos dos conteúdos que compóem o direito à educação, sobretudo no tocante à gratuidade e à obrigatoriedade. Esse fato indica, portanto, que os instrumentos internacionais de direitos humanos constituem um parâmetro mínimo de proteção, tendo a educação como um direito proteção mais ampliada na normativa nacional brasileira.

\section{Referências}

ALVES, José Augusto Lindgren. Os direitos humanos como tema global. São Paulo: Perspectiva, 2007.

BRASIL. Constituiçáo da República Federativa do Brasil: promulgada em 05 de outubro de 1988. São Paulo: Saraiva, 2008.

. Supremo Tribunal Federal. Recurso Extraordinário no 500.171-7, de 13 de agosto de 2008. Relator: Ministro Ricardo Lewandowski, Brasília, p. 1014-1029, 2008. 
. Supremo Tribunal Federal.Arguição de Descumprimento de Preceito Fundamental, ADPF no 186, Distrito Federal. Voto do Relator: Ministro Ricardo Lewandowski, Brasília, 2012.

. Lei de Cotas. Lei no 12.711, de 29 de agosto de 2012. Disponível em: http:// www.planalto.gov.br/ccivil_03/_ato2011-2014/2012/lei/l12711.htm. Acesso em: 28 de maio de 2015.

. Lei de Diretrizes e Bases da Educaçáo Nacional. Lei no 9.394, de 20 de dezembro de 1996.

CANÇADO TRINDADE, Antônio Augusto. Tratado de direito internacional dos direitos humanos. V. I. Porto Alegre: Sérgio Antônio Fabris Editor, 1997.

DONNELLY, Jack. International human rights: a regime analysis, International organization, Massachuts Institute of Techonology, 40, 3, p. 599-642, Summer, 1986.

ONU. Recopilación de instrumentos internacionales. Instrumentos de carácter universal. Volumen I (primera parte). Nueva York y Ginebra, 1994.

. PACTO INTERNACIONAL DE DERECHOS ECONÓMICOS, SOCIALES Y CULTURALES (1966). In: ONU. Recopilación de instrumentos internacionales. Instrumentos de carácter universal. Volumen I (primera parte). Nueva York y Ginebra, 1994.

. DECLARACIÓN UNIVERSAL DE DERECHOS HUMANOS (1948). In: ONU. Recopilación de instrumentos internacionales. Instrumentos de carácter universal. Volumen I (primera parte). Nueva York y Ginebra, 1994.

. CARTA DE LAS NACIONES UNIDAS. Firmada en San Francisco el 26 de junio 1945. Disponível em: www.unhchrlspanish \html\menu3\b\ch-cont_sp.html. Acesso em: 23 de maio de 2015.

POOLE, Hilary (org.). et al. Direitos humanos: referências essenciais. Tradução de Fábio Larsson. São Paulo: Editora da Universidade de São Paulo: Núcleo de Estudos da Violência, 2007.

RANGEL, Vicente Marotta. Direito e relaçóes internacionais. $8^{a}$ ed. São Paulo: Editora Revista dos Tribunais, 2005.

REZEK, Francisco. Direito internacional público: curso elementar. 11. ed. rev. e atual. São Paulo: Saraiva, 2008.

UNESCO. Los DerechosdelHombre- estudios y comentariosen torno a lanuevadeclaración universal reunidos por la UNESCO. México/Buenos Aires: Fondo de Cultura Económica, 1949, apêndice I. 